\title{
CONTRATOS E DESTRATOS ENTRE INFORMÁTICA E EDUCAÇÃO MATEMÁTICA
}

\author{
Engagements and disengagements \\ between Informatics and Mathematics Education
}

Silvana Maria Silva Iunes ${ }^{1}$. Gilberto Lacerda Santos ${ }^{2}$

Resumo: Discutem-se as aplicações pedagógicas do computador no ensino de geometria por meio de um software de representações dinâmicas. Trata-se do relato de uma investigação voltada para fazer emergir contratos e destratos entre informática e educação matemática, por meio de observações e entrevistas realizadas com alunos e uma professora em uma escola de Educação Fundamental na cidade de Brasília, DF, Brasil. Os resultados da investigação indicam diferentes possibilidades de trabalho pedagógico na área, suscetíveis de fazerem com que os contratos sobrepujem os destratos.

Palavras-chave: Educação. Educação Matemática. Informática. Tecnologia educacional.

\begin{abstract}
This article discusses the pedagogical applications for teaching geometry when making use of dynamic representation software. Engagements, or issues facilitating educational relationships, and disengagements, or troublesome issues, were carried out in some specific groups, as well as observations and interviews with primary school teachers and students in the city of Brasilia (DF). Research findings indicate different possibilities for pedagogical work in the field, and the possibility of making engagements surpass disengagements.
\end{abstract}

Keywords: Education. Mathematics Education. Computers in Education. Education technology.

\footnotetext{
1,2 Departamento de Métodos e Técnicas, Faculdade de Educação, Universidade de Brasília (UnB), campus Universitário Darcy Ribeiro, prédio FE3, sala AT 26, CEP 70600-900, Brasília, DF, Brasil. Email:

<silvanaiunes@gmail.com>
} 


\section{Introdução}

O artigo diz respeito aos contratos e destratos entre informática e educação matemática, uma relação que emerge num cenário em que o rápido avanço tecnológico impele a escola a absorver novas formas de trabalhar com os alunos utilizando o computador; em que a educação matemática também está empenhada em transformar a Matemática numa disciplina mais significativa e prazerosa para os alunos. Como atores principais, professores e alunos constroem novas formas de ensinar e aprender com a mediação do computador, gerando grandes transformações na relação educativa. Uma observação preliminar contribuiu na delimitação do problema e do local a ser pesquisado: uma escola em que a professora de Matemática se lança à utilização do computador como ferramenta de apoio do trabalho pedagógico em Geometria com alunos de $8^{\circ}$ ano do Ensino Fundamental. O objetivo de demarcar os contratos e destratos da referida relação implicou uma metodologia que envolveu a observação, grupos focais e entrevista, gerando dados que, ao serem analisados, sugeriram aspectos que facilitam a relação entre informática e educação matemática - os chamados contratos - e aspectos que dificultam tal relação - os chamados destratos. Os resultados demonstram a presença de vários contratos que fazem da relação em questão uma interessante possibilidade de trabalho. Por outro lado, há também alguns destratos que, muito mais do que dificultadores, tornam-se cuidados a serem tomados na relação estabelecida.

\section{Marco teórico geral e apresentação do problema de investigação}

A instituição escolar está, gradativamente, se transformando, ao absorver as Novas Tecnologias de Informação, Comunicação e Expressão (NTICE), denominação que atribuímos às tecnologias decorrentes da informática e que potencializam as práticas humanas de informar-se e comunicar-se, ao mesmo tempo em que disponibilizam possibilidades inéditas de livre expressão na rede mundial de pessoas conectadas por computadores (SANTOS; ANDRADE, 2010). Notam-se claramente as preocupações e os investimentos em torno das aplicações da informática na educação e muito se fala sobre as possibilidades de trabalho pedagógico mediado por esta tecnologia, suas vantagens e limitações. Mas, quais são suas reais possibilidades com relação ao enfrentamento dos problemas educacionais da atualidade? Um dos maiores desafios dos educadores é desenvolver maneiras de estimular os aprendizes a buscarem novas formas de pensar, de despertar-lhes o prazer pela busca de novos conhecimentos e de proporcionar a socialização de forma a ampliar e enriquecer conceitos e conhecimentos em relação ao mundo que os cerca. O acesso às NTICE vem promovendo essas novas formas do pensamento, necessárias para a navegação na rede mundial de computadores, para a exploração de ambientes virtuais, e para a manipulação de grande quantidade de informações, que são constantemente ressignificadas. Estas novas formas vêm justamente auxiliar os educadores a estabelecerem novos significados para a construção de novas aprendizagens, avaliando vantagens e limites do acesso às NTICE e possibilitando, assim, situações de aprendizagem que ultrapassam os limites da sala de aula convencional.

A escola desempenha um papel importantíssimo na consolidação do sujeito ao possibilitar a construção de saberes e o desenvolvimento das habilidades de agir e discernir. Com 
isso, ela estará facultando ao indivíduo a capacidade de conduzir seu próprio destino. Essa mesma escola, quando efetivamente inserida na teia sócio digital que é a internet, tem a informática educativa como exemplo de uma estratégia que vem contribuir para o desenvolvimento dessas habilidades e da possibilidade de o sujeito estar inserido em diferentes formas de aprendizagem colaborativa e construtiva, percebendo-se participante ativo desse processo, de forma criativa e dinâmica. Assim, lidar com a informática implica novos pensares, assim como novos pensares criam, no sujeito, o desejo de novas relações com a informática. Informática e novas estruturas do pensar andam de mãos dadas: uma conduz à outra (PRENSKY, 2001).

Paralelamente a esse indicativo de apropriação da informática pela instituição escolar, há todo um movimento de ressignificação das disciplinas escolares e de reestruturação de seu tratamento didático, tendo em vista as novas estruturas de pensamento, oriundas da sociedade atual. No bojo desse amplo movimento de mudança, a educação matemática tem avançado na direção de uma desmistificação do mito que faz da Matemática uma disciplina 'bicho papão', responsável por grandes fracassos escolares, gerando nos alunos um sentimento de aversão que leva ao desinteresse, tornando-os incapazes de perceber a importância dela no seu cotidiano. De fato, a Matemática é tradicionalmente a disciplina que gera 'repugnância' na maioria dos alunos, especialmente porque, na maior parte das vezes, é tratada, na sala de aula, de modo descontextualizado, distante das possibilidades reais de sua aplicação. Gómez-Granell (1997) confirmou esta dificuldade com a Matemática. Entretanto, a autora afirma que a maior parte das pessoas pode aprendê-la sem dificuldade alguma, desde que tal aprendizagem esteja vinculada a contextos e a situações que sejam cultural e socialmente significativos. Esta afirmação confirma a necessidade de definir novas formas, contextos e significados para que as aprendizagens matemáticas possam ser alcançadas satisfatoriamente pela sociedade.

D’Ambrósio (1998), concebendo a Matemática como arte e técnica de compreensão e explicação da natureza e das relações do homem com a natureza, define o "fazer matemática" como a construção de ferramentas mentais que ajudam o homem a compreender-se a partir das relações que ele estabelece com o mundo, seu espaço, seu tempo. A atividade matemática, nessa concepção, atrela-se de forma obrigatória ao pensamento, às estruturas operatórias, à construção e à utilização de conceitos. Portanto, falar em educação matemática exige considerar os espaços socioculturais que favorecem ao sujeito pensante (ser epistêmico) construir e estruturar os objetos de pensamento que possibilitam a compreensão e a explicação de seu mundo a partir da contagem, medida, estimativa, representação gráfica etc. (MUNIZ, 2000).

São grandes os esforços no sentido de tornar a Matemática uma linguagem natural nas escolas. Entretanto, ela deve constituir-se linguagem do pensamento humano, aplicada e em constante construção. As pesquisas científicas em educação matemática já vêm trazendo subsídios que compõem uma série de atividades para o auxílio do ensino e da aprendizagem da Matemática, tornando-a mais prazerosa e recheada de contextualizações e explicações práticas, o que tem implicado investimentos importantes na formação inicial e continuada dos professores.

Muito se tem falado sobre o uso da informática no ensino e na aprendizagem da Matemática, a partir de um pressuposto de que a introdução do computador na educação matemática permite ao sujeito escolher, entre inúmeros percursos, o que melhor favoreça sua construção da aprendizagem (NEVES, 2008). O esquema de aprendizagem desenvolvido via informática é individual, pertencente a cada um. Contudo, o produto final desse conhecimen- 
to poderá até ser o mesmo (pois se trata aí de Matemática). O que será modificado agora, com o auxílio da ferramenta da informática, é o caminho escolhido para construir esta aprendizagem, o processo percorrido pelo sujeito e os meios utilizados por ele. Diferentes algoritmos de resolução podem ser estabelecidos para se chegar a uma mesma resposta para um mesmo problema. Assim, em educação matemática, como em informática, a resolução de uma situação-problema não é mais a resposta numérica final, mas o processo construído para obtê-la, processo que pode variar de sujeito a sujeito.

Infelizmente, ainda hoje o ensino e a aprendizagem de Matemática privilegiam métodos e algoritmos padronizados, ou seja, apenas uma maneira de chegar a um determinado conhecimento. Não é oportunizada a vivência/experimentação, dentro de um grupo de alunos, de outras maneiras de resolver determinadas questões, mas somente mediante o modelo apresentado pelo professor. No entanto, o avanço tecnológico nos conduz a não mais aceitar modelos de resolução prontos. Muito pelo contrário, permite escolher aquele que nos irá melhor satisfazer, a fim de construirmos nossas aprendizagens.

Para exemplificar a afirmativa acima, pode-se utilizar uma ferramenta bastante conhecida do computador, que é um editor de texto qualquer. Ao utilizar essa ferramenta podem-se escolher muitos caminhos para executar determinado comando, por ícones diferentes: desenhos ou palavras. Cada sujeito escolherá seu caminho para a resolução de uma mesma tarefa. É a partir das necessidades de cada usuário que esses programas são construídos e essas possibilidades de escolher caminhos estão cada vez mais presentes nas ferramentas que são construídas para serem utilizadas na resolução de problemas. Pode-se compreender, assim, como o ambiente informatizado vem corroborar a ideia de descentralização da concepção de chegar ao resultado final. Efetivamente, é no processo desencadeado para alcançar esse resultado que o educador matemático deve focar sua mediação para identificar, valorizar, socializar, confrontar os mais diferentes processos de resolução de uma situação-problema, seja ela matemática ou não.

A partir dessa ideia, segundo a qual o aluno pode estar continuamente construindo suas aprendizagens, propondo, testando, confrontando, revendo hipóteses, percorrendo desse modo seus próprios caminhos para alcançá-las, pode-se pensar a educação matemática trabalhada com a utilização do computador no ensino e aprendizagem de alguns conteúdos, com base em pressupostos de que a utilização do computador possibilitará ao aluno desenvolver sua aprendizagem num ritmo próprio, de forma que, na construção, ele possa trilhar, a partir de avanços e retrocessos, sem o olhar recriminador do professor. De fato, a 'máquina' está sob seu comando e ela jamais irá julgar seu ritmo. Outro pressuposto, importante na utilização do computador no ensino e na aprendizagem de conteúdos matemáticos, é a possibilidade de o aluno desenvolver atividades em uma velocidade muito superior à de um professor, agilizando com isso todo o processo educativo.

Diante da perspectiva explicitada e da possibilidade do uso da informática na educação matemática encontra-se um cenário empírico que favoreceu a investigação relatada neste texto: a escola - o professor de Matemática - o aluno.

Comecemos pelo professor de Matemática, que é visto pela sociedade como um profissional de inúmeras habilidades, capaz de 'ensinar' uma série de conteúdos que servirão 
para os alunos no futuro. Por sua vez, este professor acredita e espera que vai conseguir transmitir todos estes conteúdos para seus alunos, pois anos de formação superior o habilitaram e o impregnaram desta missão. Ao chegar à sala de aula, ele percebe imediatamente que a maioria dos conteúdos que propõe não faz sentido algum para os alunos, que não veem uma aplicação prática e sim uma bagagem necessária para ser utilizada no vestibular.

Já os alunos de hoje não são mais tão passivos com o que lhes é proposto. Eles estão cada vez mais questionadores e investigadores de seus próprios processos, sobretudo quando entram na fase da adolescência, espaço para criticar o criticado, negar o aceito, desestabilizar o estabilizado. Querem muito mais do que se pode oferecer. Além disso, estão totalmente inseridos no mundo das NTICE, onde são bombardeados por todos os lados por meios tecnológicos que hoje a sociedade oferece, inclusive por intermédio das instituições educacionais.

As instituições, por sua vez, estão incentivando fortemente o uso das NTICE, como discute Santos (2011). Nas instituições públicas, o incentivo é financiado por programas de governo, fazendo com que o ritmo da informatização seja bem menor que nas instituições particulares. Estas últimas investem significativos recursos no aparato tecnológico para que tenham, acima de tudo, instrumentos de atração e diferenciação de mercado. Porém, as instituições, tanto públicas como particulares, veem-se como reféns dos professores, de quem dependem os esforços reais, no dia a dia da sala de aula, para empregarem as NTICE como meios de ensino e de aprendizagem, como recursos do trabalho docente.

Mas, como este trabalho é feito? Qual o impacto dessa proposta no aluno? Como o professor, mediador, coloca-se diante dessa utilização? Como o conteúdo pode ser trabalhado com a mediação do computador? Quais as reais modificações no ensino e na aprendizagem de conteúdo matemático quando ela se realiza via computadores? $\mathrm{O}$ aprendiz realmente modifica sua representação da aula de Matemática a partir do uso da informática? Quais as vantagens de trabalhar com o ambiente de informática para o ensino e a aprendizagem da Matemática? A simples migração para a sala de aula virtual cria melhores condições de ensino e aprendizagem? Isso tem relação com a utilização do computador? O computador mascara as reais insatisfações com a Matemática ou realmente desmistifica as dificuldades ora percebidas pelo aluno? Estaríamos nós, educadores, apropriando-nos de meios modernos para melhorar nossa prática que, por sua vez, estaria tornando-se cada vez pior?

Essas questões contribuíram como elementos de reflexão para conduzir a questão central da pesquisa: quais são os 'contratos e destratos' entre informática e educação matemática? Os contratos são os aspectos facilitadores, cuidados, avanços, as contribuições, possibilidades, construções e convergências do uso da informática na educação matemática. Os destratos são os aspectos dificultadores, descuidos, retrocessos, limitações, impossibilidades e divergências entre a informática e a educação matemática, sobretudo no que se refere à interação aluno, professor e conhecimento matemático com a mediação do computador.

Para se identificar elementos de resposta a esta questão de pesquisa, delimitamos nossa investigação em torno da observação não-participante de uma série de relações educativas de educação matemática mediada pelo computador em uma escola privada de Brasília, DF, Brasil. 


\section{Marco teórico específico e método de investigação}

Se tomarmos como objetivos fundamentais da educação criar homens que sejam capazes de fazer novas coisas e não de simplesmente repetir o que outras gerações fizeram, homens que sejam criativos, inventores e descobridores, e formar mentes que possam ser críticas, que possam analisar e não aceitar tudo que lhes é oferecido (PIAGET, 1969), é fundamental que ocorram mudanças nos propósitos vigentes em favor de uma abordagem construtivista, em que o conhecimento passa a ser visto como um processo de construção. Então, resolver um problema não é chegar a um resultado direto, devendo ser valorizado todo o processo de construção que nos leva a uma solução. Segundo Piaget (1969), numa abordagem construtivista, a mediação entre o conhecimento e o objeto a ser conhecido ocorre nas ações do sujeito. Assim, a ação de resolver um problema é tão ou mais importante do que o resultado numérico obtido. Mas o desenvolvimento cognitivo não depende somente de processos de construções mentais individuais. Depende, também, de interações sociais norteadas por relações de cooperação. Piaget (1969) enfatiza que a inteligência humana somente se desenvolve no indivíduo em função de interações sociais que são, em geral, demasiadamente negligenciadas. Ele considera o ser social de mais alto nível aquele que consegue relacionar-se com seus semelhantes de forma equilibrada. Ainda segundo o autor, tornar-se social é um processo evolutivo e é, na medida em que o eu renuncia a si mesmo para inserir seu ponto de vista entre outros e se curva às regras da reciprocidade, que o indivíduo torna-se personalidade. Para Piaget (1969), o processo da socialização é parte dos processos de maturação e evolução. Contudo, se para Piaget (1969) a criança torna-se ser social, para Vigotsky (1988), a criança é ser social desde que nasce. Tais diferenças influenciam na forma de conceber a mediação realizada pelo adulto na construção do conhecimento matemático.

Ao nosso entender, as contribuições de Vigotsky (1998) podem aportar melhores contribuições do conhecimento matemático mediado pelo computador. Segundo Vigotsky (1998), a interação social realizada a partir da necessidade da resolução cooperativa de uma situaçãoproblema é fonte de aprendizagem. Tal posição teórica é importante em nosso estudo, que objetiva compreender a mediação do conhecimento matemático via ambiente informatizado. Essa interação foi fundamental nas análises dos dados decorrentes de nossa investigação.

De fato, diversas pesquisas indicam que, aplicado à educação matemática, o computador coloca o aluno em situações de aprendizagem que exigem dele duas formas distintas de pensamento, indispensáveis ao processo de construção de conhecimento, no sentido próprio do termo: por um lado, o rigor, a lógica e o método e, por outro, o pensamento livre, intuitivo e a criatividade. Essa exigência envolve geralmente um aspecto importante na educação, o fator lúdico, que pode ser amplamente contemplado pelo computador no emprego dessa tecnologia no Ensino Fundamental e Médio, como indicam diversos estudiosos do assunto (LION, 1996; LITWIN, 1997), além de nossa própria experiência docente (MUNIZ; IUNES, 2004).

Entre as inúmeras vias de trabalho no campo da educação matemática, a informática educativa acena, ao menos teoricamente, com possibilidades pedagógicas inovadoras que precisam ser consideradas e com relação às quais grandes números de pesquisas têm se posicionado favoravelmente. É importante evidenciar que, nos meios educacionais, já é consenso que todo esforço e investimento em informática educativa para fornecer os resultados almejados precisam estar devidamente enquadrados em uma política educacional consistente. É, tam- 
bém, crucial que, nestes tempos em que se planeja distribuir tablets para cada aluno da Educação Básica, tentemos avançar na concepção e na proposição de estratégias para que o computador seja cada vez mais adequadamente utilizado no contexto da relação educativa, tendo em vista, sobretudo, que a grande maioria das iniciativas nesse campo ocorre em meios acadêmicos e não encontra ressonância na outra ponta do sistema, isto é, no espaço escolar, na sala de aula, no cotidiano da escola. Com isso, a população brasileira em geral, sobretudo a classe trabalhadora, permanece a quilômetros de distância das possibilidades de trabalho envolvendo a informática educativa. Com trinta milhões de alunos no Ensino Básico e taxa de analfabetismo só inferior, na América Latina, à da Bolívia, o ensino público de nosso país procura acertar-se entre o giz e a informática e precisa ser trabalhado em dois tempos: de um lado, na luta por condições mínimas de funcionamento da escola e, de outro, na luta pela recuperação do atraso tecnológico por meio de investimentos de porte em tecnologia educativa de ponta.

Ora, a aprendizagem matemática é um processo em constante construção, seu desenvolvimento só acontece através do 'fazer matemática' - experimentar, interpretar, visualizar, conjecturar, estabelecer relações, abstrair, generalizar - e não mediante apresentação formal de um corpo de conhecimento, da transmissão ordenada de palavras, de símbolos e até mesmo de raciocínio. Papert (1985), um dos pioneiros na introdução da informática na educação, afirmava que o computador pode nos permitir mudar os limites entre o concreto e o formal. Com isso, sugeriu que a utilização do computador poderia contribuir para o desenvolvimento do 'fazer matemática' com base no fato de ele proporcionar a realização de experimentos, permitir a elaboração de inúmeras interpretações e visualizações gráficas, favorecer o estabelecimento de relações, comparações etc. Mas, nós nos damos a liberdade de questionar: "o computador na sala de aula de matemática é garantia de tais mudanças? Até que ponto?”.

Parece-nos que, no que tange a educação matemática praticada atualmente, estamos distantes dessa realidade, uma vez que ainda se privilegia a transmissão verbal - ou por meio de figuras, de forma ordenada e pronta, de forma exterior ao aluno, pouco compreensível, difícil e praticamente sem sentido algum. Seria a introdução de informática uma via de transformação de tal realidade? Que contribuição a informática educativa pode oferecer na evolução da educação matemática?

As questões específicas apresentadas nesta seção do texto concluem a delimitação de nossa investigação, que foi realizada em uma escola da rede privada do Distrito Federal, com alunos do $8^{\circ}$ ano do Ensino Fundamental da classe média alta de Brasília. Os alunos tinham cinco aulas de Matemática por semana, sendo que duas eram destinadas ao estudo da geometria. No primeiro tempo dessas aulas, a professora trabalhava em sala e, no segundo tempo, no laboratório de informática. Lá, os alunos tinham a missão de aplicar a geometria trabalhada pela professora em sala de aula utilizando softwares de representação geométrica suscetíveis de promoverem o desenvolvimento de habilidades de investigação, exploração, descoberta, formulação de hipóteses ou conjecturas e que podiam partir da observação e ir até a justificativa geométrica de forma relativamente simples.

Inicialmente, foram feitas observações livres das relações educativas no laboratório de informática, a partir das quais realizaram-se outras, dirigidas para um contexto (utilização do computador na aprendizagem matemática). Após estas observações dirigidas, selecionamos um grupo de alunos que compuseram o grupo focal. Simultaneamente fizemos entrevista com a professora. Esses dois momentos foram gravados em vídeo (grupos focais) e em grava- 
dor (entrevista com a professora). Partimos, então, para a fase de transcrição desses registros e, numa outra análise, avaliamos a necessidade de entrevista também com alguns alunos, finalizando, assim, o processo da coleta de dados. Encerrada essa etapa, iniciamos a triangulação dos dados, de maneira a identificar e compreender a natureza da dinâmica instaurada na utilização do computador no ensino e aprendizagem da Matemática. O confronto entre as observações dirigidas, o grupo focal com os alunos e a entrevista com a professora compôs a base da investigação de maneira a explicitar os contratos e destratos buscados.

Com base nas observações e entrevistas com os grupos focais, constituímos algumas categorias para nos orientarem na identificação dos contratos e destratos visados: cognitiva, funcional, didático-pedagógica e socioafetiva. Tais categorias foram constituídas a partir das próprias relações que os observados (professora e alunos) tinham acerca da geometria e de como a trabalhavam na relação educativa.

A categoria cognitiva se refere às situações em que os alunos demonstram avançar em aprendizagens efetivas. A categoria funcional se refere às situações de manipulação da informática para 'facilitar as coisas', o que dispensa o uso de material (régua, compasso, transferidor etc.) e agiliza, com eficiência, todo um trabalho manual a ser feito para o estudo da geometria. A categoria didático-pedagógica diz respeito ao modo como a professora organizou a aula no laboratório de informática. A última categoria, definida como socioafetiva, refere-se a abordagens motivacionais e relacionais entre professora e alunos, sempre com o objetivo de se promoverem aprendizagens significativas. Na seção seguinte, apontamos alguns contratos e destratos mais significativos observados no decorrer da investigação.

\section{Contratos e destratos observados na relação entre informática e educação matemática}

Os primeiros contratos observados surgiram no contexto de diversas situações entrecruzando duas categorias de observação: a cognitiva e a funcional. Tais situações foram aquelas em que os alunos, motivados pelas atividades propostas pela ferramenta informática, investiram, de forma concentrada e persistente, no desenvolvimento das atividades e na resolução dos problemas propostos pelo professor. Nesses momentos, uma forte ambiência de trabalho reinou na sala de aula, o que evidenciou dois contratos didáticos incontornáveis para o sucesso de toda relação de ensino e de aprendizagem: o engajamento dos atores e a colaboração entre eles para, por meio da manipulação de ferramentas, avançarem em aprendizagens significativas e pertinentes.

Por outro lado, várias situações enquadradas na categoria funcional - que se refere à ferramenta informática - permitiram que vislumbrássemos outro elemento de contrato didático entre informática e educação matemática: o dinamismo. De fato, a informática, em função de suas características, permite a dinamização de situações por meio de animações, simulações, sons e uso de formas e cores. Com relação a esse elemento de contrato, fortemente reconhecido entre os alunos, percebe-se o quanto ele é motivador para o desenvolvimento das atividades propostas.

Outro contrato observado, desta vez vinculado à categoria socioafetiva, está relacionado aos pontos positivos da relação educativa a ser desenvolvida em um contexto de trabalho 
colaborativo, com os alunos trabalhando em dupla. A oportunidade de descobrir e de aprender ao mesmo tempo em que um colega pareceu ser algo bastante significativo para a maioria dos pesquisados, o que evidencia a importância de o educador matemático estar atento aos ambientes com essas possibilidades de interações sociais. Esse contrato é valorizado pelos alunos como fundamental elemento motivador para a execução da atividade. Parece que na aula convencional, mesmo estando em salas com média de trinta alunos, eles se sentem sozinhos. A única possibilidade de estabelecer relações de aprendizagem com outros colegas, de compartilhar experiências de aprendizagem e de trocar ideias está no espaço proporcionado pela aula mediada pela informática, que tem uma proposta de ser colaborativa.

Vigotsky (1998) afirma que a construção do conhecimento matemático se dá na interação social entre os sujeitos. Portanto, a utilização do computador dessa forma nas aulas de Matemática passa a ser uma excelente oportunidade de exercício da interação. Por outro lado, o fato de os alunos estarem juntos na sala de aula convencional não parece estar sendo evidenciado como espaço interativo suficientemente coeso para proporcionar a construção de conhecimentos matemáticos. Na realização da aula de Matemática via computador, essa interação social vislumbrada por Vigotsky (1998) aparece materializada nas trocas entre pares provocadas pela informática. Independentemente da opção do professor em empregar um computador como apoio para sua ação docente, é inegável que os alunos são levados a constituir um ambiente de trocas e de confrontos, situação que foi evidenciada por eles como sendo de difícil estabelecimento em sala de aula convencional.

Em contrapartida, um elemento de destrato didático surge no contexto dessa mesma observação e dessa mesma categoria. Ou seja, quando a atividade matemática é eminentemente solitária, desprovida de interações sociais com seus pares, quando as trocas são aceitas exclusivamente com o professor, ela se torna difícil, mais complicada e menos engajadora. Além desse fator, observa-se, também, um outro contrato importante, apontado pelos próprios alunos, desta vez relacionado à categoria didático-pedagógica. Trata-se de uma diferença qualitativa e significativa da mediação docente, que se coloca mais próxima dos alunos, tanto física quanto cognitivamente, não apenas mediando, mas também participando da resolução dos problemas. Ela desloca-se de sua tradicional posição dominante, protagonista, e adota uma postura próxima aos alunos, de aprender juntamente com eles, numa mediação propícia para uma investigação conjunta.

Outro importante contrato didático encontrado na relação entre informática e educação matemática parte também da categoria didático-pedagógica. Trata-se das situações em que a professora opta por buscar a 'cultura informática' dos alunos e trazê-la para a sala de aula, a fim de fazê-los sentirem-se mais à vontade na manipulação dos conceitos matemáticos por meio da própria informática. Com esse movimento, ela procurou inserir a Matemática num ambiente em que os alunos sentem muito prazer em atuar, o que poderá influenciar positivamente a relação deles com o tema.

Ainda no contexto da categoria didático-pedagógica, outro elemento de contrato bastante interessante foi o roteiro proposto pela professora, altamente aceito pelo grupo e reconhecido como de grande importância e eficiência para o desenvolvimento da atividade. Ao oferecer um roteiro para os alunos, a professora não só os estimulou a desenvolverem a autonomia, como também assumiu que, dentro de uma relação educativa mediada pela informática, a figura do professor não pode competir com o computador. Em outras palavras, quando 
os alunos interagem com conhecimentos e informações por meio de computadores, eles estão direcionados para trabalhar com a máquina. Caso o professor resolva explicar oralmente algum processo, ele jamais terá a atenção irrestrita dos alunos, que estão diante do computador. O foco, o centro de interesse para o aluno, é a ferramenta que ele quer utilizar como mediadora de suas investigações e descobertas, restando ao professor estar disponível para, de acordo com a necessidade de cada um, ser solicitado individualmente. Além disso, o roteiro é uma excelente estratégia de ação pedagógica para a utilização do computador, podendo mesmo ser visto como um instrumento mediador paralelo à máquina, pois, além de descentralizar o papel do professor como gerenciador das atividades, contribui para o desenvolvimento da habilidade de ressignificar os espaços pedagógicos de uso do computador num contexto de investimento nas mudanças do quadro atual da educação matemática.

Por outro lado, um elemento de destrato didático surgiu do fato de a informática ter sido utilizada apenas para o trabalho com a geometria. O uso do computador para o auxílio de conteúdos matemáticos ficou reduzido unicamente a essa parte da disciplina, ficando tantas outras possibilidades de uso desconhecidas pelos alunos. Vê-se, então, a necessidade de diversificação em relação à aplicação em diferentes conteúdos de Matemática. Isso sugere não só uma intensa necessidade de investigação por parte dos educadores matemáticos como também de pesquisadores que venham a contribuir com possibilidades e limites de outras ferramentas suscetíveis de apoiarem a aprendizagem de outros conteúdos.

\section{Considerações finais}

A análise final da relação entre informática e educação matemática na experiência dessa investigação possibilita fazer algumas considerações que poderão contribuir para futuras experiências e investigações em torno dessas questões.

A proposta de trabalhar informática como ferramenta de auxílio à aprendizagem de conteúdos matemáticos ainda parece um processo um tanto embrionário. Alguns fatores inibem o desenvolvimento satisfatório dessa relação, porque a informática aplicada à educação implica uma verdadeira mudança de postura com relação aos paradigmas educacionais ainda existentes, sobretudo no que se refere à postura do professor de Matemática, que pode chegar ao princípio lúdico naturalmente presente no ambiente informatizado e, mesmo assim, garantir a permanência de características da aula tradicional. O mais importante, segundo crença do professor, é preservar aprendizagens que só podem existir a partir de determinadas 'formatações’ da organização do espaço pedagógico, sobretudo, centrado nele próprio. Muitas são as barreiras a serem rompidas a fim de visualizar o avanço educacional exigido nos dias atuais.

A possibilidade de interação direta entre os alunos e o computador delineia uma nova dinâmica de trabalho que permite o livre fluxo de aprendizagens. No cerne dessa dinâmica, a mediação do professor estará mais centrada no incentivo à autonomia do aluno em desenvolver as atividades utilizando a informática, e com isso, construir novos conhecimentos que irão contribuir para uma melhor compreensão da Matemática. Embora esse processo seja percebido em plena construção, acredita-se que ele pode ser considerado uma porta de entrada para os educadores matemáticos repensarem sua prática, a fim de que, ao propor esses ambientes ricos em estímulos propiciando novas formas de aprendizagem, possam gerar melhor com- 
preensão, significação e consequente representação social positiva da própria Matemática e de sua aprendizagem.

Contudo, não se pode atribuir à utilização do computador nas aulas de Matemática o papel de 'salvador da pátria' da educação. Muitos outros fatores podem contribuir para a melhoria da qualidade do ensino de Matemática. O projeto pedagógico da escola, investimentos na formação dos professores, a melhoria das políticas públicas a fim de que possibilitem maior acesso às novas tecnologias também são fatores importantes e fundamentais que devem ser considerados para a conquista da melhoria da qualidade do ensino de Matemática. Além disso, é necessário um redimensionamento do currículo na busca de um instrumento de liberação e autonomia articulado em torno de propostas interdisciplinares em que a aprendizagem integrada, criativa, dinâmica e significativa possa ser incentivada como prática em todos os ambientes escolares. Outro ponto importante é a transformação do papel do professor, que passa a ser mediador de trabalhos diversificados nos mais variados ambientes, sejam eles com ou sem a utilização de computador. Em sua mediação, o educador organizará atividades significativas centradas nas necessidades e interesses de quem aprende, e não nos conteúdos a serem trabalhados, e, com isso, estimulará o desenvolvimento da autonomia e criatividade, de forma a incitar novas formas de construção de conhecimentos.

Um ponto a ressaltar no final desse estudo foi o desafio de delimitar a questão de pesquisa. Muitas são as questões que perpassam esse tema e, a partir de um movimento contínuo de investigação de possibilidades de trabalho a fim de melhorar o ensino e a aprendizagem da Matemática, a escolha de uma única questão foi uma grande dificuldade. Os contratos e destratos entre informática e educação matemática foram investigados a fim de melhor demarcar essa relação, uma vez que não se pode acreditar que as novas tecnologias, sobretudo o computador, vêm resolver todas as dificuldades inerentes à aprendizagem da Matemática, e, consequentemente a seu ensino.

Nesta perspectiva, outras investigações poderiam ser desenvolvidas a partir desse estudo, girando em torno de questões, tais como: quais habilidades docentes precisariam ser enfatizadas em um currículo de formação de professores para lidarem adequadamente com o computador no ensino de Matemática? A relação entre alunos e professores com o conteúdo é alterada quando o computador é inserido como mediador do ensino e da aprendizagem? Que leitura faria a etnomatemática tendo em vista o impacto da 'cultura informática' na educação matemática? Que programas de computador podem contribuir efetivamente para o ensino e a aprendizagem da Matemática? Eis algumas questões suscetíveis de gerarem estudos interessantes, que correspondem a reais necessidades de pesquisa e que podem, tanto quanto esta, contribuir para o avanço dos conhecimentos nos campos da educação matemática e das aplicações das tecnologias na educação.

A título de conclusão do trabalho, e à luz da análise realizada, é possível enfatizar que a relação entre informática e educação matemática é extremamente favorável - tanto para o professor quanto para o aluno -, contribuindo para que ocorram processos de construção de conhecimentos mais significativos, pertinentes e contextualizados. De fato, os contratos observados foram substantivamente mais relevantes do que os destratos. Apesar de serem dificultadores reais da relação mencionada, apontam muito mais para aspectos que podem ser melhorados do que para aspectos que impossibilitam o uso do computador no ensino de Matemática. Por outro lado, os contratos apontados caracterizam o computador como um 
Iunes, S. M. S.; Santos, G. L.

poderoso instrumento para subsidiar a ação docente com novas possibilidades de trabalho pedagógico, baseadas, sobretudo, em uma reinvenção dos papéis de todos os atores da relação educativa. Entre contratos e destratos, pode-se dizer que o computador, usado adequadamente na escola, tem uma contribuição efetiva a oferecer.

\section{Referências}

D’AMBRÓSIO, U. Educação matemática: da teoria à prática. 4. ed. Campinas: Papirus, 1998.

DANYLUK, O. Alfabetização matemática: as primeiras manifestações da escrita infantil. Porto Alegre: Sulina, 1998.

GÓMEZ-GRANELL, C. A aquisição da linguagem matemática: símbolo e significado. In: TEBEROSKY, A.; TOLCHINSKY, L. (Org.). Além da alfabetização. São Paulo: Ática, 1997. p. 257-282.

LION, C. G. Mitos e realidades na tecnologia educacional. In: LITWIN, E. (Org.).

Tecnologia educacional: política, histórias e propostas. Porto Alegre: Artes Médicas, 1996. p. 9-12.

LITWIN, E. Questões e tendências da pesquisa no campo da tecnologia educacional. In: LITWIN, E. (Org.). Tecnologia educacional: políticas, histórias e propostas. Porto Alegre: Artes Médicas, 1997. p. 112-118.

MUNIZ, C. A. Fundamentos de educação para séries iniciais: módulo do PIE Pedagogia Inicio de Escolarização. Brasília: Universidade de Brasília, 2000.

\section{MUNIZ, C. A.; IUNES, S. M. S. Fundamentos teóricos e metodológicos da} matemática: fascículo didático. Brasília: Ludoteca, 2004.

NEVES, R. S. P. A divisão e os números racionais: uma pesquisa de intervenção psicopedagógica sobre o desenvolvimento de competências conceituais de alunos e professores. 2008. 533 f. Tese (Doutorado em Psicologia) - Instituto de Psicologia, Universidade de Brasília, Brasília, 2008.

PAPERT, S. A máquina das crianças: repensando a escola na era da informática. Porto Alegre: Artes Médicas, 1985.

PIAGET, J. Psicologia e pedagogia. Rio de Janeiro: Forense, 1969. 
PRENSKY, M. Digital natives, digital immigrants, part 1. On the Horizon, Bingley, v. 9, n. 5, p. 1-6, Oct. 2001.

SANTOS, G. L. Uma pesquisa longitudinal sobre professores e computadores. Educação e Realidade, Porto Alegre, v. 36, n. 2, p. 43-59, set./dez. 2011.

SANTOS, G. L.; ANDRADE, J. B. F. de. Virtualizando a escola: migrações docentes rumo à sala de aula virtual. Brasília: LiberLivros, 2010.

VIGOTSKY, L. S. Pensamento e linguagem. 2. ed. São Paulo: Martins Fontes, 1998. 